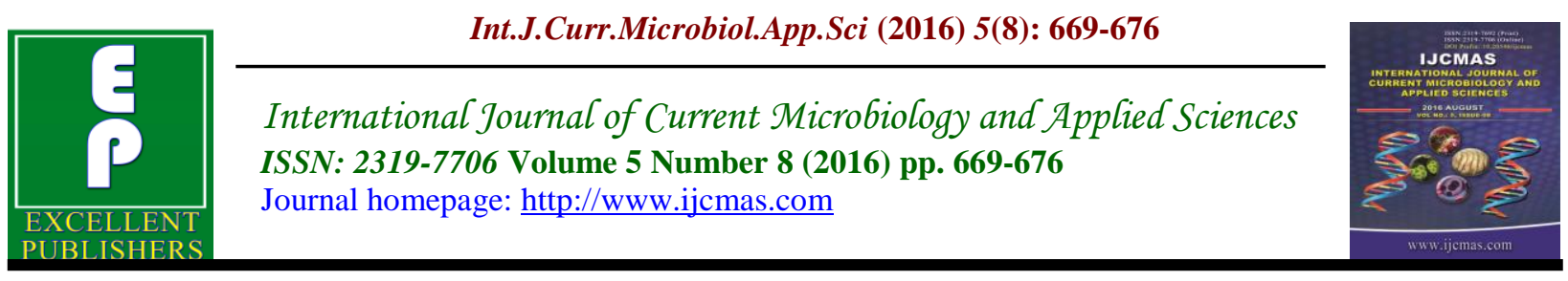

Original Research Article

http://dx.doi.org/10.20546/ijcmas.2016.508.076

\title{
Dengue NS1 Antigen - An Important Early Diagnostic Tool for Diagnosis of Dengue Infection
}

\author{
Shanta Shubhra Das*, Dilip Turbadkar, Sujata Baveja, Chaya A. Kumar, \\ Mrudul Randive and Anita Ramchandran
}

Department of Microbiology, Lokmanya Tilak Municipal Medical College \& GH, Sion, Mumbai, Maharashtra, PIN - 400 022, India

*Corresponding author

\begin{abstract}
A B S T R A C T
Keywords

Dengue,

Early detection,

NS1 antigen,

Demographic profile, Point of care test.

\section{Article Info}

Accepted:

28 July 2016

Available Online:

10 August 2016

Earliest detection of dengue infection and its complications in our resource-poor country is a grave challenge. It certainly reduces dengue associated mortality and morbidity. For this purpose, we set out to determine if the dengue NS1 antigen ELISA could be used as a point of care test to predict severe disease. 356 clinically suspected dengue patients with $\mathrm{h} / \mathrm{o}<5$ days fever admitted in a tertiary care hospital were enrolled in this study. Clinical and laboratory parameters were recorded and the serum samples were tested using Panbio Dengue Early Elisa kit (Panbio, Australia) for detection of dengue NS1 antigen. In the study group ( $\mathrm{N}=356)$, $25.28 \%$ were found to be reactive for dengue NS1 antigen. Maximum Seropositivity $(55.56 \%)$ was seen in the age group of $15-45$ years with the male:female ratio $=2: 1$. Clinical features were significantly correlated with dengue seropositivity. $92.22 \%$ seropositive patients were found to be thrombocytopenic. It was highly significant $(\mathrm{p}<0.001)$. Dengue NS1 antigen is an important marker for early diagnosis of dengue infection, especially in the window period when dengue antibodies are not available in blood. Thrombocytopenia is an accessory laboratory finding to predict the impending complications (DHF, DSS).
\end{abstract}

\section{Introduction}

Dengue is the most common arboviral infection, caused by four serotypes of Dengue virus, i.e. DEN-1, DEN-2, DEN-3 and DEN-4 belonging to the genus Flavivirus and family Flaviviridae (Johnson et al., 2005). It is the second most important mosquito borne infection in terms of morbidity and mortality.

Humans are the main amplifying host of the virus. It is spread through the bite of infected female Aedes aegypti and Aedes albopictus mosquitoes.

The spectrum of diseases ranges from undifferentiated fever to more severe forms of Dengue haemorrhagic fever (DHF) or Dengue shock syndrome (DSS). DHF and DSS are the leading cause of hospitalization and death particularly among children. It affects up to 100 million people every year with 5,00,000 cases of Dengue 
haemorrhagic fever (DHF) and Dengue shock syndrome (DSS) and about 30,000 deaths (Guzmán et al., 2002). Case fatality rates in endemic countries are $2.5 \%$ (Guzmán et al., 2002). During epidemics of dengue, attack rates among susceptible are 40-90\% (Chaturvediet al., 2004).

Dengue virus is an enveloped positive sense RNA virus. The genomic RNA is $11 \mathrm{~kb}$ in length and composed of three structural protein genes that encode for nucleocapsid or core protein $(\mathrm{C})$, a membrane-associated protein (M) and an envelope protein (E) and seven non-structural (NS) protein(NS1, NS2a, NS2b, NS3, NS4a, NS4b, and NS5) (Guzmán et al., 2002). Amongst nonstructural proteins, NS1 is a highly conserved glycoprotein and is essential for viral replication. It is produced both in membrane-associated and secretory form by the virus (Dussart et al., 2006). During acute viral infection NS1 is found to be associated with intracellular organelles. The hexameric form of NS1 protein is also present in the sera of the patients during the acute phase of illness.

Although the majority of dengue infections result inself-limited Dengue fever (DF), some develop fluid leakage and bleeding manifestations which result in Dengue haemorrhagic fever (DHF) and Dengue shock syndrome (DSS) (Martina et al., 2009).In case of severe infection in children or secondary infection in adults presenting before $5^{\text {th }}$ day of illness, where clinical features are severe from beginning and the patient is rapidly deteriorating, clinically evidenced by hypotension, tachycardia, epistaxis, haemoptysis, oliguria, requires immediate diagnosis for further and early management of the patient. Therefore, in such patients intense monitoring of vital parameters i.e. pulse rate, blood pressure, urine output, oxygen saturation is required.
Laboratory monitoring of serum ureacreatinine, platelet count, haematocrit, coagulation profile has utmost importance in the prevention of shock and impending death of the patients. Sometimes, it is impossible to provide required health care facilities in resource poor many dengue affected countries.

There are lots of laboratory procedures for the diagnosis of dengue infection e.g. viral culture and detection by Fluorescent antibody test, viral RNA detection by reverse transcriptase-PCR (RT-PCR) and detection of anti-dengue virus antibody by Haemagglutination inhibition [HI], Complement fixation test [CF], Neutralization test, Immunoglobin (IgM) capture Enzyme-Linked Immunosorbent Assay (MAC-ELISA) and Rapid IgM strip test (Wang et al., 2010). Both viral culture and RT-PCR are gold standard, confirmatory tests but time consuming and costly procedures (Shrivastava et al., 2011). In case of antibody detection, it has to wait for 5 days to appear dengue $\operatorname{IgM}$ antibody in the sera of infected patients(Shrivastava et al., 2011). As viral antigen is present in the patient serum from the very $1^{\text {st }}$ day of illness, detection of antigen has utmost importance for early detection of dengue virus infection (Alcon et al., 2002). NS1 antigen is not only group-specific but also type-specific determinants and of benefit for early rapid diagnosis due to its long half-life in blood. Many commercial assays are currently available for the detection of dengue NS1 antigen. Among these tests, the Panbio Early Dengue NS1 Capture ELISA has shown to have an overall sensitivity of $67 \%$ and a specificity of $99 \%$ (Zhang et al., 2014).

However, performing viral culture or RTPCR in all patients admitted to hospitals in resource poor countries is impossible. 
Therefore, we proceeded to determine whether NS1 antigen detection could be used as a point of care test to predict the risk of developing fatal dengue infection.

\section{Materials and Methods}

\section{Patients}

The study was carried out over a period of one year (in 2013) in the Department of Microbiology at Lokmanya Tilak Municipal Medical College \& Government Hospital, a tertiary care hospital in Mumbai, India with bed strength of over 1400. 356 clinically suspected dengue patients as per WHO criteria, admitted throughout the year with history of fever for $<5$ days, were enrolled following informed written consent. The study was approved by the Institutional Ethical Committee and also by Maharashtra University of Health Sciences. Clinical features such as fever, headache, retroorbital pain, myalgia, arthralgia, presence ofany bleeding manifestations and of any possible fluid accumulation in the pleural cavity and abdomen were monitored at the time of admission tohospital and regularly afterwards, until they were discharged. Bleeding manifestations may be of wide range of variety in severe form of disease i.e. petechiae, ecchymosis, epistaxis, haematemesis, melena or the presence of per vaginalbleeding in the absence of the monthly period in women (Tewari et al., 2013). Serology: $5 \mathrm{ml}$ of blood was collected from clinically suspected dengue patients in a sterile vacutainer aseptically. Serum was separated by centrifugation at $2000 \mathrm{rpm}$ for 15 minutes. The serum samples were preserved in sterile vials at $20^{\circ} \mathrm{C}$ and testing was carried out using Panbio Dengue Early Elisa kit following kit literature instructions.

Serum Dengue NS1 antigen when present, binds to anti-NS1 antibodies attached to the polystyrene surface of the micro well test strips. Residual serum was removed from the assay plate by washing. HRPConjugated Anti-NS1 Mab was added to the assay plate. After incubation at $37^{\circ} \mathrm{C}$ for 1 hour, the micro wells were washed and a colourless substrate system, tetramethylbenzidine / hydrogen peroxide was added. The substrate was hydrolysed by the enzyme and the chromogen changed to blue colour. Colour development was indicative of the presence of dengue NS1 antigen in the test sample. One external positive and negative control each were put to validate the test procedure.

\section{Statistical Analysis}

Statistical analysis was performed using IBM Statistical Package for the Social Sciences version 20 (SPSS v20, IBM). Categorical variables between two groups were compared using Chi-square test and Fisher's exact test. A $p$ value of $<0.05$ was considered significant.

\section{Results and Discussion}

Of the 356 patients, 90 (25.28\%) were found to be reactive for dengue NS1 antigen. Amongst them, 50 (55.56\%) patients belonged to the age group of 15-45 years with mean age 32.21 years. Male to female ratio among dengue seropositive patients was $2: 1$. (Table 1)

In the study group $(n=356), 84.44 \%(76 / 90)$ patients were seropositive for dengue NS1 antigen in clinically suspected Dengue fever, followed by DSS (6.67\%) and DHF $(5.56 \%)$.(Table 2$)$

All patients in the study group were suffering from fever, in fact, the inclusion criteria were clinically suspected dengue patients admitted with fever of $<5$ days duration. Headache 
(72.22\%) and myalgia (63.33\%) were also present in large number of patients. Regarding bleeding manifestations, rash $(52.22 \%)$ and petechiae $(41.11 \%)$ were found mostly, followed by mucocutaneous bleeding (31.11\%), gum bleeding (13.33\%), epistaxis (10\%) and gastro-intestinal bleeding (5.56\%). All correlated significantly with dengue seropositivity. (Table 3)

In our study, a total of $92.22 \%(83 / 90)$ dengue seropositive patients were thrombocytopenic [platelet count $\left.<1,00,000 / \mathrm{mm}^{3}\right]$. Maximum $41.11 \%$ patients had platelet count between 20,000$50,000 / \mathrm{mm}^{3}, 40 \%$ patients between 50,000 $1,00,000 / \mathrm{mm}^{3}$ followed by $11.11 \%$ patient having platelet count $\leq 20,000 / \mathrm{mm}^{3}$. Thrombocytopenia was significantly correlated with dengue NS1 seropositivity. It was more prevalent in extremes of age group (Table 4).

For a long time, dengue $\operatorname{IgM}$ antibody detection by Immunochromatography (ICT) or Enzyme Linked Immuno-Sorbant Assay (ELISA) has been the mainstay of diagnosis of dengue infection. The dengue-specific antibodies begin to appear at around $5^{\text {th }}$ day of fever in primary infection (Shrivastava $e t$ al., 2011). Even in most secondary infections, both the $\mathrm{IgM}$ and $\mathrm{IgG}$ type antibodies cannot be recorded before $3^{\text {rd }}$ day. So, there is always a window period when only dengue antibodies are tested. A new parameter, dengue NS1 antigen, now available for diagnosis of dengue infection, is detectable from day 1 in both primary and secondary infection. NS1 antigen level varies from $0.04-2 \mu \mathrm{g} / \mathrm{ml}$ in acute-phase serum samples (Shu et al., 2003). This is the reason of its higher detection rate in acutephase sera.

In this study, the results obtained were analyzed and evaluated. Dengue NS1 antigen reactivity was $25.28 \%$ in the study group. This finding was comparable with the studies of Jayashree et al., 2011 and Shrivastava et al., 2011 in clinically suspected patients with a male: female ratio of 2:1. Maximum seropositive patients 50 $(55.56 \%)$ belonged to the age group of 1545 years composed of young-working male population. Similar data was obtained by a study conducted by Stephen et al., 2014. The reactivity gradually decreased towards extremes of age group [Table 1]. It indicates higher rate of transmission of dengue infection due to the spread of the disease at the workplace especially in offices and construction sites having various sites for adequate survival and reproduction of the mosquito and the day-time transmission of the disease.

In the present study, according to the WHO criteria, dengue virus infection was classified into undifferentiated fever, Dengue fever (DF), Dengue haemorrhagic fever (DHF) and Dengue shock syndrome (DSS) which can form the basis for initiating early and appropriate management. Dengue seropositivity was most prevalent in patients having clinically suspected Dengue fever $(84.44 \%)$, followed by DSS $(6.67 \%)$ and DHF (5.56\%) [Table 2] (Figure I). Here, patients of Dengue fever outnumbered Dengue haemorrhagic fever and Dengue shock syndrome patients. This finding also correlated with predominance of Dengue fever in Brazil and other countries in South America shown by Vicente et al., 2012 in their study. This indicates early diagnosis and appropriate management through administration of antipyretics, intravenous fluid resuscitation and monitoring of vitals and urine output. Moreover, due to the prevalence of only one serotype of dengue virus in this geographical area, the incidence of DHF and DSS was found to be relatively low. 
It was evident in the study, that symptoms and signs were significantly correlated with the serodiagnosis of dengue virus infection (Table 3). Therefore, clinical suspicion and appropriate presumptive diagnosis of the infection according to $\mathrm{WHO}$ guidelines has utmost importance in reducing morbidity and mortality due to dengue infection.

Laboratory findings such as thrombocytopenia (platelet count $\left.<1,00,000 / \mathrm{mm}^{3}\right)$ is an important parameter for diagnosis of impending Dengue haemorrhagic fever (DHF) and Dengue shock syndrome (DSS). It is more prevalent in secondary cases when infected by a different serotype, observed by day 3-4 of the illness. Thrombocytopenia may be occasionally observed in DF but is a constant feature and one of the diagnostic criteria of DHF and DSS. These are the life threatening complications of dengue infection. The decreasing platelet counts have found to predict the severity of the disease - the lower the counts, the more severe the disease.

Table.1 Dengue Seropositivity among Study Group (N=356)

\begin{tabular}{|c|c|c|c|c|c|c|}
\hline \multirow{2}{*}{$\begin{array}{c}\text { Age Group } \\
\text { (Years) }\end{array}$} & \multicolumn{2}{|c|}{ Male } & \multicolumn{2}{c|}{ Female } & \multicolumn{2}{c|}{ Total } \\
\cline { 2 - 7 } & Tested & Reactive & Tested & Reactive & Tested & $\begin{array}{c}\text { Reactive } \\
(\%)\end{array}$ \\
\hline$\leq \mathbf{1 5}$ & 50 & 11 & 36 & 6 & 86 & $\begin{array}{c}17 \\
(19.77)\end{array}$ \\
\hline $\mathbf{1 5 - 3 0}$ & 42 & 13 & 21 & 7 & 63 & $\begin{array}{c}20 \\
(31.75)\end{array}$ \\
\hline $\mathbf{3 0 - 4 5}$ & 65 & 19 & 29 & 11 & 94 & $\begin{array}{c}30 \\
(31.91)\end{array}$ \\
\hline $\mathbf{4 5 - 6 0}$ & 51 & 13 & 26 & 4 & 77 & $\begin{array}{c}17 \\
(22.08)\end{array}$ \\
\hline $\mathbf{2 6 0}$ & 17 & 4 & 19 & 2 & 36 & $\begin{array}{c}6 \\
(16.67)\end{array}$ \\
\hline Total & $\mathbf{2 2 5}$ & $\mathbf{6 0}$ & $\mathbf{1 3 1}$ & $\mathbf{3 0}$ & $\mathbf{3 5 6}$ & $\begin{array}{c}\mathbf{9 0} \\
(\mathbf{2 5 . 2 8})\end{array}$ \\
\hline
\end{tabular}

Table.2 Dengue Seropositivity in Clinically Suspected Cases $(\mathrm{N}=356)$

\begin{tabular}{|c|c|c|c|c|}
\hline & $\begin{array}{c}\text { Clinically } \\
\text { Suspected Cases }\end{array}$ & $\begin{array}{c}\text { Dengue } \\
\text { Seropositivity }\end{array}$ & $\begin{array}{c}\text { Percentage } \\
(\mathbf{\%})\end{array}$ & p value \\
\hline Undifferentiated fever (UF) & 32 & 3 & 3.33 & 0.015 \\
\hline Dengue fever (DF) & 302 & 76 & 84.44 & 0.453 \\
\hline $\begin{array}{c}\text { Dengue haemorrhagic fever } \\
(\text { DHF) }\end{array}$ & 13 & 5 & 5.56 & $0.210^{*}$ \\
\hline $\begin{array}{c}\text { Dengue shock syndrome } \\
(\text { DSS) }\end{array}$ & 9 & 6 & 6.67 & $0.010^{*}$ \\
\hline Total & $\mathbf{3 5 6}$ & $\mathbf{9 0}$ & $\mathbf{2 5 . 2 8}$ & \\
\hline \multicolumn{4}{|c}{$\left(p=\right.$ Chi-square test, $p^{*}=$ Fischer's exact test $)$}
\end{tabular}


Table.3 Clinical Features in Seropositive Patients $(\mathrm{N}=90)$

\begin{tabular}{|c|c|c|c|}
\hline Clinical Features & $\begin{array}{c}\text { Dengue } \\
\text { Seropositivity }\end{array}$ & $\begin{array}{c}\text { Percentage } \\
(\boldsymbol{\%})\end{array}$ & (p value) \\
\hline Fever & 90 & 100 & - \\
\hline Headache & 65 & 72.22 & $<0.001$ \\
\hline Myalgia & 57 & 63.33 & $<0.001$ \\
\hline Arthralgia & 15 & 16.67 & $<0.001$ \\
\hline Vomiting & 43 & 47.78 & $<0.001$ \\
\hline Rash & 47 & 52.22 & $<0.001$ \\
\hline Petechiae & 37 & 41.11 & $<0.001$ \\
\hline Gum bleeding & 12 & 13.33 & $<0.001^{*}$ \\
\hline Epistaxis & 9 & 10.00 & $<0.001^{*}$ \\
\hline Mucocutaneous bleeding & 28 & 31.11 & $<0.001$ \\
\hline G.I. bleeding & 5 & 5.56 & $0.005^{*}$ \\
\hline
\end{tabular}

( $p=$ Chi-square test, $p^{*}=$ Fischer's exact test $)$

Table.4 Thrombocytopenia in Study Group (N=356)

\begin{tabular}{|c|c|c|c|}
\hline \multirow{2}{*}{$\begin{array}{c}\text { Dengue } \\
\text { Seropositivity }\end{array}$} & \multicolumn{2}{|c|}{ Thrombocytopenia } \\
$\left(<1,00,000 / \mathbf{m m}^{3}\right)$ & \multirow{2}{*}{ p value } \\
& YES & NO & \\
\hline Yes & 83 & 7 & \multirow{2}{*}{$<0.001$} \\
\hline No & 4 & 262 & \\
\hline Total & $\mathbf{8 7}$ & $\mathbf{2 6 9}$ & \\
\hline
\end{tabular}

\begin{tabular}{|c|c|c|c|}
\hline $\begin{array}{c}\text { Platelet count } \\
\left(/ \mathbf{m m}^{3}\right)\end{array}$ & Dengue & Percentage & p value \\
\hline$\leq \mathbf{2 0 , 0 0 0}$ & 10 & 11.11 & $<\mathbf{0 . 0 0 1} *$ \\
\hline $\mathbf{2 0 , 0 0 0}-\mathbf{5 0 , 0 0 0}$ & 37 & 41.11 & $<\mathbf{0 . 0 0 1}$ \\
\hline $\mathbf{5 0 , 0 0 0}-\mathbf{1 , 0 0 , 0 0 0}$ & 36 & 40.0 & $<\mathbf{0 . 0 0 1}$ \\
\hline
\end{tabular}

Fig.1 Dengue Reactivity in Clinically Suspected Cases (N=356)

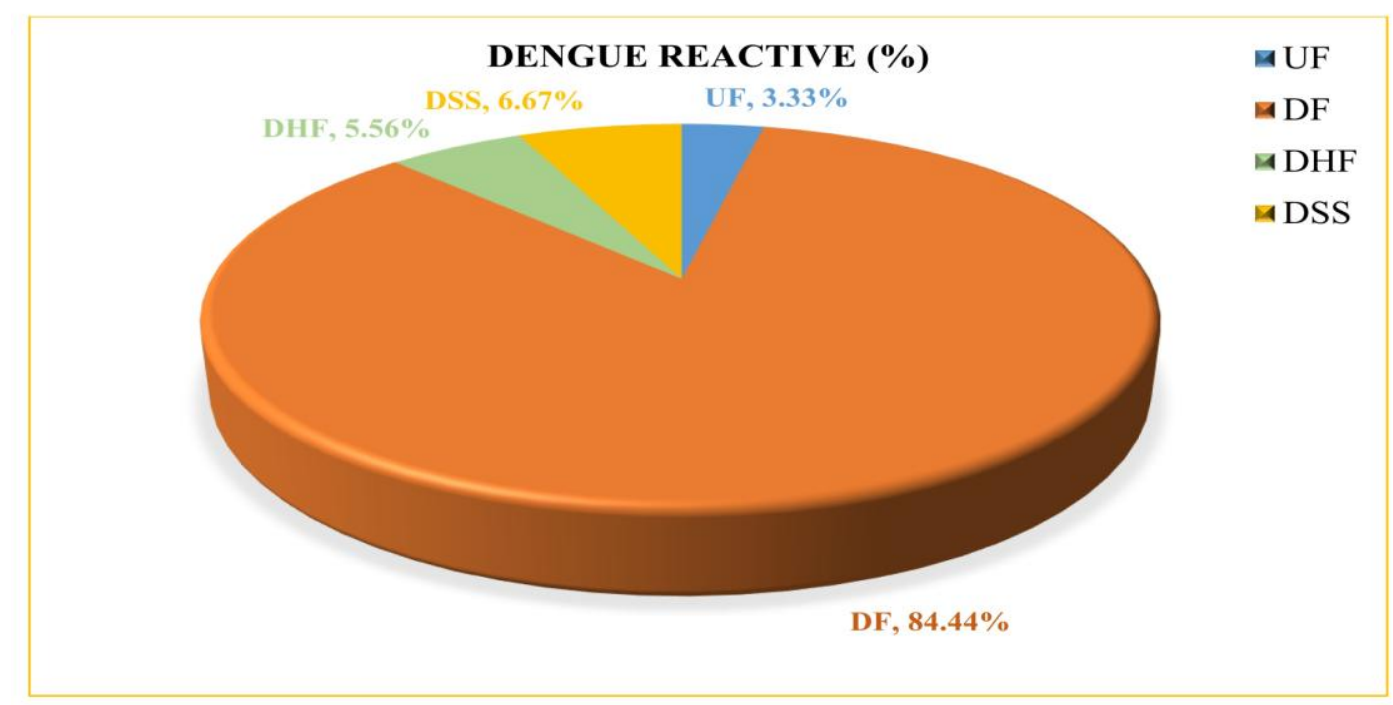


In this study, thrombocytopenia was prevalent in $92.22 \%$ of dengue seropositive patients. It was significantly correlated ( $p$ $<0.001)$ with dengue seropositivity. Studies conducted by Tewariet al., 2013 Chhina et al., 2009 and Roy et al., 2013 correlated with the findings of our study.

In conclusion, this study was performed at a tertiary care hospital. It is worth mentioning here that most tertiary care teaching hospitals lack in viral culture or PCR set up. Therefore, applying gold standard tests (Viral culture, PCR) in studies related to viral infections are out of reach in these centres. Dengue is an infection that is present in urban, semi-urban and rural areas. Advanced technological set up is available only at very few elite laboratories. It is important to conduct studies in the peripheral centres where the laboratory is to function without great technological backup and still is expected to provide reasonable opinion to the clinician in the management of infections like dengue.

In our study, young-adult male population was the predominant victim of the disease. Fever was the most consistent clinical feature, followed by headache, myalgia, rash and vomiting. Most common haemorrhagic manifestation was mucocutaneous bleeding; followed by petechiae and epistaxis. Thrombocytopenia correlated significantly with dengue virus infection. Moderate thrombocytopenia was present in most of the seropositive patients. Therefore, it may be used as an accessory laboratory finding for early diagnosis of Dengue fever (DF), Dengue haemorrhagic fever (DHF) and Dengue shock syndrome (DSS).

\section{References}

Alcon, S., Talarmin, A., Debruyne, M., Falconar, A., Deubel, V., Flamand, M. 2002. Enzyme-Linked Immunosorbent
Assay Specific to Dengue Virus Type 1 Nonstructural Protein NS1 Reveals Circulation of the Antigen in the Blood during the Acute Phase of Disease in Patients Experiencing Primary or Secondary Infections. $J$. Clin. Microbiol., 40(2): 376-81.

Chaturvedi, U.C.S.R. 2004. Dengue Haemorrhagic Fever: A Global Challenge. Indian J. Med. Microbiol., 22(1): 5-6.

Chhina, D.K., Goyal, O., Goyal, P., Kumar, R., Puri, S,. Chhina, R.S. 2009. Haemorrhagic manifestations of dengue fever \&amp; their management in a tertiary care hospital in north India. Indian J. Med. Res., 129(6): 718-20.

Dussart, P., Labeau, B., Lagathu, G., Louis, P., Nunes, M.R.T. 2006. Rodrigues SG, et al. Evaluation of an Enzyme Immunoassay for Detection of Dengue Virus NS1 Antigen in Human Serum. Clin. Vaccine Immunol., 13(11): 1185-9.

Guzmán, M.G., Kouri, G. 2002. Dengue: an update. Lancet Infect. Dis., 2(1): 3342.

Jayashree, K., Manasa, G.C., Pallavi, P., Manjunath, G.V. 2011. Evaluation of Platelets as Predictive Parameters in Dengue Fever. Indian J. Hematol. Blood Transfus., 27(3):127-30.

Johnson, B.W., Russell, B.J., Lanciotti, R.S., 2005. Icrobiol JCLINM. SerotypeSpecific Detection of Dengue Viruses in a Fourplex Real-Time Reverse Transcriptase PCR Assay. J. Clin. Microbiol., 43(10): 4977-83.

Martina, B.E.E., Koraka, P., Osterhaus, A.D.M.E. 2009. Dengue Virus Pathogenesis: an Integrated View. Clin. Microbiol. Rev., 22(4): 564-81.

Roy, A., Sarkar, D., Chakraborty, S., Chaudhuri, J., Ghosh, P., Chakraborty, S. 2013. Profile of hepatic 
involvement by dengue virus in dengue infected children. $N$. Am. $J$. .Med. Sci., 5(8):480-5.

Shrivastava, A., Dash, P.K., Tripathi, N.K., Sahni, A.K., Gopalan, N. 2011. Evaluation of a commercial Dengue NS1 enzyme-linked immunosorbent assay for early diagnosis of dengue infection. Indian J. Med. Microbiol., 29(1): 51-5.

Shu, P.Y., Chen, L.K., Chang, S.F., Yueh, Y.Y., Chow, L., Chien, L.J., et al. 2003. Comparison of Capture Immunoglobulin $\mathrm{M}$ (IgM) and $\operatorname{IgG}$ Enzyme-Linked Immunosorbent Assay (ELISA) and Nonstructural Protein NS1 Serotype-Specific IgG ELISA for Differentiation of Primary and Secondary Dengue Virus Infections. Clin. Diagn. Lab. Immunol., 10(4):622-30.

Stephen, S., Charles, M.V., Anitharaj, V., Deepa, C., Umadevi, S. 2014. Early dengue diagnosis by nonstructural protein 1 antigen detection: Rapid immunochromotography versus two the enzyme-linked immunosorbent assay kits. Indian J. Pathol. Microbiol., 57(1):81-4.

Tewari, K.N., Tuli, N.R., Devgun, S.C. 2013. Clinical profile of dengue fever and use of platelets in four tertiary level hospitals of Delhi in the year 2009. J. Indian Acad. Clin. Med.,14:812.

Vicente, C.R., Lauar, J.C., Santos, B.S., Cobe, V.M., Cerutti Junior, C. 2013. Factors related to severe dengue during an epidemic in Vitoria, State of Espirito Santo, Brazil, 2011. Rev. Soc. Bras. Med. Trop., 46: 629-32.

Wang, S.M., Sekaran, S.D. 2010. Evaluation of a Commercial SD Dengue Virus NS1 Antigen Capture Enzyme-Linked Immunosorbent Assay Kit for Early Diagnosis of Dengue Virus Infection. J. Clin. Microbiol., 48(8): 2793-7.

Zhang, H., Li, W., Wang, J., Peng, H., Che, X., Chen, X., et al. 2014. NS1-based tests with diagnostic utility for confirming dengue infection: A metaanalysis. Int. J. Infect. Dis. Int. Soc. Infect. Dis.,26: 57-66.

\section{How to cite this article:}

Shanta Shubhra Das, Dilip Turbadkar, Sujata Baveja, Chaya A. Kumar, Mrudul Randive and Anita Ramchandran. 2016. Dengue NS1 Antigen - An Important Early Diagnostic Tool for Diagnosis of Dengue Infection. Int.J.Curr.Microbiol.App.Sci. 5(8): 669-676. doi: http://dx.doi.org/10.20546/ijcmas.2016.508.076 